Buana Sains Vol 19 No 2 : 79 - 84, 2019

\title{
ANALISIS FAKTOR-FAKTOR YANG MEMPENGARUHI PRODUKSI KOPI MASYARAKAT DI KEC. DAMPIT, KAB. MALANG
}

\author{
Inosensius Harmin Jandu, Nur Ida Iriani dan Dyanasari \\ Sekolah Pascasarjana Jurusan Ekonomi Pertanian \\ Universitas Tribhuwana Tunggadewi
}

\begin{abstract}
Plantation sub-sector is part of the agricultural sector which acts as one of the country's foreign exchange-earners, producer of consumption materials, producers of raw materials for industry, employment providers and encourages agribusiness and supports environmental conservation. The role of plantations is increasing along with the creation of resilient agriculture by utilizing natural resources optimally supported by quality human resources. In this study, the analytical method used is multiple regression analysis models with the help of the SPSS program (for Windows version 25.0). The results showed that the Land Area X1 variable was at a significance level of $95 \%(\alpha=$ $0.05)$. Then it means $(0.033<0.005)$ which means that $\mathrm{H} 0$ is rejected and $\mathrm{Ha}$ is received by the land area and has a significant positive effect on coffee production in Dampit Subdistrict, Labor an X2 significance level of $95 \%(\alpha=0.05$. Then $0.246>0.05$, which means $\mathrm{H} 0$ is received and $\mathrm{Ha}$ is rejected, then labor has a positive but not significant effect on coffee production in Dampit Sub-district. Superior seedlings at X3 are 95\% significance level $(\alpha=0.05$. Then $0,000<0.05$, which means $\mathrm{H} 0$ is rejected and $\mathrm{Ha}$ is accepted, so superior seedlings have a significant positive effect on coffee production in Dampit District, Fertilizer X4 at a significance level of $95 \%(\alpha=0.05$. then $0.005<0.05$ which means $\mathrm{H} 0$ is rejected and $\mathrm{Ha}$ is accepted) Fertilizers have a significant positive effect on coffee production in Dampit District. Pesticides at X5 at a significance level of $95 \%(\alpha=0.05$. So that means $(0.927>0.05)$ which means that $\mathrm{H} 0$ is accepted and $\mathrm{Ha}$ is rejected then pesticides have a positive but not significant effect on coffee production in Dampit District.
\end{abstract}

Keywords: Analysis; coffee; community; Dampit Subdistrict; production.

\section{Pendahuluan}

Indonesia merupakan negara yang memiliki keunggulan sebagai negara agraris dengan bertumpu pada sektor pertanian. Salah satu bagian dari sektor pertanian adalah sub sektor perkebunan. Sub sektor perkebunan merupakan bagian dari sektor pertanian yang berperan sebagai salah satu penghasil devisa negara, penghasil bahan konsumsi, penghasil bahan baku bagi industri, penyedia lapangan kerja serta mendorong agribisnis dan mendukung konservasi lingkungan. Peranan perkebunan semakin meningkat seiring dengan terciptanya pertanian yang tangguh dengan memanfaatkan sumberdaya alam secara optimal didukung oleh sumberdaya menusia yang berkualitas.

Perkebunan kopi di indonesia di dominasi oleh perkebunan rakyat dengan total lahan mencapai $96 \%$ dari total lahan di indonesia, sedangkan lahan yang di kuasai oleh negara berupa perkebunan 
I. H. Jandu, N. I. Iriani dan Dyanasari/ Buana Sains Vol 19 No 2 : 78-84

besar negara dan perkebunan besar swasta hanya berjumlah $4 \%$ dari total lahan kopi di indonesia. Ekspor kopi mempunyai peran yang cukup penting dalam pertumbuhan devisa. Hal ini dapat menjadi satu indikasi bahwa tanaman kopi memegang peran yang penting dalam perekonomian nasional baik dari segi pembiayaan pembangunan, kesempatan kerja maupun dalam peningkatan kesejahteraan petani khususnya dan masyarakat umumnya. Produksi serta ekspor kopi Indonesia yang tinggi juga dilakukan untuk memenuhi kebutuhan kopi dunia yang semakin meningkat.

Dampit adalah salah satu Kecamatan Di Kabupaten Malang, Provinsi Jawa Timur, Indonesia. Secara umum kecamatan dampit memiliki komoditas utama kopi. Sejak masa penjajahan Belanda, Kabupaten Malang, khususnya Kecamatan Dampit bagian selatan merupakan daerah penghasil kopi. Sesuai dengan Tekstur tanah dan cocok dengan letak georgrafis yang sesuai, yakni berada di ketinggian 500 hingga 600 meter dari permukaan laut (Mdpl), tanaman kopi di daerah itu masih bertahan hingga sekarang. Data yang ada di Dinas Tanaman Pangan, Hortikultura dan Perkebunan Kabupaten Malang menunjukkan, pada tahun 2016, Kecamatan Dampit mampu menghasilkan biji kopi sebanyak 2.280 ton dengan luas areal perkebunan mencapai 3.373 hektar.

\section{Metode Penelitian}

Lokasi Penelitian dilakukan di Kecamatan Dampit yang berlokasi di 6 Desa, tempat penelitian di tentukan secara purposive, berdasarkan pertimbangan bahwa kecamatan dampit merupakan penghasil kopi terbesar Di Kabupaten Malang, dan mayoritas masyarakat tersebut adalah petani kopi.

\section{Penentuan Populasi Dan Sampel}

Menurut Sugiyono (2017:80), definisi populasi adalah sebagai berikut: Populasi adalah wilayah generalisasi yang terdiri atas obyek/subyek yang mempunyai kualitas dan karakteristik tertentu yang ditetapkan oleh peneliti untuk dipelajari dan kemudian ditarik kesimpulannya.

Menurut Sugiyono (2017:81) Sampel adalah bagian dari jumlah dan karakteristik yang dimiliki oleh populasi tersebut. Kecamatan dampit memiliki 12 Desa, dan sampel yang akan digunakan sebanyak 6 desa dikarenakan jumlah petani kopi di 6 desa tersebut produksinya tinggi di bandingkan dengan desa yang lain. Populasi dari keenam desa tersebut yang perkebunan kopi berjumlah 3.500 petani dengan Rumus slovin: 100 petani

\section{Hasil Dan Pembahasan}

\section{Persamaan Regresi Linear Berganda}

Analisis Regresi Linier Berganda digunakan untuk mengetahui besarnya pengaruh variabel-variabel bebas terhadap variabel terikat. Berdasarkan perhitungan melalui komputer dengan menggunakan program SPSS (For Windows Versi 25,0). Berikut dibawah ini adalah hasil uji regresi linier berganda: Menunjukkan hasil pengujian analisis regresi liner berganda akhirnya dapat disusun persamaan regresi linier berganda pada penelitian sebagai berikut:

$\mathrm{Y}=0.097 \mathrm{X} 1+0.077 \mathrm{X} 2+0.532 \mathrm{X} 3+$ $0.247 \mathrm{X} 4+0.006 \mathrm{X} 5+\mathrm{e}$

Adapun interpretasi dari persamaan tersebut adalah :

a. Konstanta sebesar 8.440 artinya jika tingkat luas lahan (X1), tenaga kerja (X2), bibit unggul (X3), pupuk (X4) dan pestisida (X5) nilainya adalah 0 , maka produksi kopi (Y) nilainya sebesar 8.440 . 
b. Koefisien regresi variabel luas lahan (X1) sebesar 0.097 artinya jika tingkat luas lahan mengalami kenaikan 1 satuan, maka variabel Produksi kopi (Y) akan mengalami kenaikan sebesar 0.097, Koefisien bernilai positif artinya terjadi pengaruh positif antara tingkat luas lahan dengan produksi kopi.

c. Koefisien regresi variabel tenaga kerja (X2) sebesar 0.077 artinya jika tingkat tenaga kerja mengalami kenaikan 1 satuan, maka variabel produksi kopi (Y) akan mengalami peningkatan sebesar 0.077, Koefisien bernilai positif artinya terjadi pengaruh positif antara tingkat tenaga kerja dengan produksi kopi.

d. Koefisien regresi variabel bibit unggul (X3) sebesar 0.532 artinya jika tingkat bibit unggul mengalami kenaikan 1 satuan, maka variabel produksi kopi (Y) akan mengalami peningkatan sebesar 0.532 Koefisien bernilai positif artinya terjadi pengaruh positif antara tingkat bibit unggul dengan produksi kopi.

e. Koefisien regresi variabel pupuk (X4) sebesar 0.247 artinya jika tingkat pupuk mengalami kenaikan 1 satuan, maka variabel produksi kopi (Y) akan mengalami peningkatan sebesar 0.247 , Koefisien bernilai positif artinya terjadi pengaruh negatif antara tingkat pupuk dengan produksi kopi.

f. Koefisien regresi variabel pestisida (X5) sebesar 0.006 artinya jika tingkat pestisida mengalami kenaikan 1 satuan, maka variabel produksi kopi (Y) akan mengalami peningkatan sebesar 0.006, Koefisien bernilai positif artinya terjadi pengaruh positif antara tingkat pestisida dengan produksi kopi.

\section{Implikasi Produksi Kopi Terhadap Kesejahteraan Petani}

Kesejahteraan petani merupakan prasyarat agar pembangunan pertanian bisa berhasil dan berjalan secra berkelanjutan, berbagai program terobosan yang di yakini dapat meningkatkan kesejahteraan petani kopi salah satunya mendongkrak produktivitas kopi. Dalam meningkatkan pertumbuhan produksi kopi, dapat dilakukan dengan optimalisasi pemanfaatan sumberdaya lahan, berupa pengembangan areal tanam melalui ekstensifikasi dan intensifikasi, berikut ini adalah upaya yang dapat dilakukan dalam jangka panjang untuk meraih produksi kopi di Kec. Dampit.

\section{Produksi Pendapatan Dan Kesejahteraan}

Kesejahteraan petani merupakan prasyarat agar pembangunan pertanian bisa berhasil dan berjalan secara berkelanjutan, berbagai program terobosan yang diyakini dapat meningkatkan kesejahteraan petani kopi salah satunya mendongkrak produktivitas kopi. Dalam meningkatkan pertumbuhan produksi kopi, dapat dilakukan dengan optimalisasi pemanfaatan sumberdaya lahan, berupa pengembangan areal tanam melalui ekstensifikasi dan intensifikasi, berikut ini adalah upaya yang dapat dilakukan dalam jangka panjang untuk meraih produksi kopi di Kec. Dampit.

Untuk mendapatkan suatu barang yang dan dapat di gunakan serta bermanfaat kemudian juga bernilai adalah kebaganggan setiap orang, jika itu adalah kebutuhan penting atau funndamental tentu perlu diperlu sediakan berkontinu, apabila kemudian kebutuhan itu adalah komoditi pertanian yang berperan terhadap pendapatan masyarakat sehinggga bukan tidak mungkin di kembangkan bahkan eksitensi harus di jaga sedemikian rupa. Terkait dengan 
kebutuhan tersebut diatas korelasinya terhadap komoditi yang di riset ini adalah bagiamana produksi itu berimplikasi dengan kesejahteran.

\section{Kesimpulan}

Berdasarkan hasil analisis data seperti yang telah diuraikan sebelumnya, maka dapat disimpulkan bahwa:

1. Faktor yang mempengaruhi produksi kopi luas lahan, tenaga kerja, bibit unggul, pupuk dan pestisida memiliki pengaruh positif terhadap jumlah produksi kopi di Kecamatan Dampit. Pengaruh dari setiap faktor variabel luas lahan (0.097) , tenaga kerja (0.077), bibit unggul (0.532), pupuk (0.247), dan pestisida (0.006) maka dengan demikian untuk mendapatkan produksi yang lebih maksimal petani harus bisa mengoptimum fakor produksi.

2. Nilai absolut koefisien beta yang dilakukan yang paling besar adalah luas lahan, bibit unggul dan pupuk yang berarti bahwa proses produksi kopi di Kecamatan Dampit bersifat padat terhadap luas lahan, bibit unggul dan pupuk.

3. Implikasinya terhadap masyarakat petani dampit berdasarkan hasil analisis bahwa apabila tidak memperhatikan faktor produksi bisa memepengaruhi juga terhadap kesejahteraan petani khususnya untuk pendapatan para petani.

\section{Daftar Pustaka}

Direktorat Jenderal Perkebunan. 2016. Statistik Perkebunan Indonesia: Kopi 2017. Kementerian Pertanian. Jakarta.

Ellis, Markman. 2011. The CoffeeHouse: a Cultural History. Hachette. United Kingdom.
Gudjarati.

1995. Ekonometrika Dasar,Terjemahan. Erlangga. Jakarta.

Gordo, Sheila M.C., Pinheiro, Daniel G., Moreira, Edith C.O., Rodrigues, Simone M., Poltronieri, Marli C., Lemos, Oriel F De., Tojal, Israel., and R.T.J. Ramos (2012). Highthroughput sequencing of black pepper root transcriptome. Plant Biology, 12, 168.

Husodo. 2004. Pertanian Mandiri. PT Raja Grafindo. Jakarta.

Indrawanto., S. Joni Munarso. 2010. Budidaya dan Pasca Panen Kopi. Pusat Penelitian dan Pengembangan Perkebunan. Bogor.

Joesron dan Fathorrozi. 2003. Teori Ekonomi Mikro. Salemba Empat. Jakarta. Miller, Roger Le Roy, Meiners, Roger E. 2000. Teori Ekonomi Intennediate.

Mubyarto. 2011. Pengantar Ekonomi Pertanian. LP3ES, Jakarta.

Nicholson, Walter. 2002. Ekonomi Intennediate dan Aplikasinya Edisi Kedelapan. Terjemahan IGN Bayu Mahendra dan Abdul Aziz. Erlangga. Jakarta.

Rismayani, R. dan I.W. Laba. (2015). Hama utama pada pembibitan lada dan pengendaliannya. Prosiding Seminar Perbenihan Tanaman Rempah Dan Obat, 223-232.

Risnadewi, Tri. 2013. Analisis Efisiensi Produksi Kopi Robusta Di Kabupaten Temanggung (Studi Kasus Di Kecamatan Candiroto), Jurnal: Litbang Jawa Tengah,Vol 11 No 1-Juni 2013. Badan Penelitian Dan Pengembangan 
Provinsi Jawa Tengah,

Temanggung.

Soekartawi, 2011. Teori Ekonomi

Produksi Dengan Pokok Bahasan

Analisis Fungsi Cobb-Douglas.

PT Raja Grafindo Persada.

Jakarta.

Soetopo, D. (2012). Pengendalian hama penggerek batang lada menghadapi isu pembatasan residu pestisida. Pengembangan Inovasi Pertanian, 5(1), 32-43.

Sudaryati, Endang. 2004. Analisis faktorfaktor yang Mempengaruhi

Produksi Kopi Rakyat Di Kabupaten Temanggung. Jurnal: Litbang Jawa Tengah,Vol 09 No 1-Mei 2004. Badan Penelitian Dan Pengembangan Provinsi Jawa Tengah, Temanggung.

Samuelson. 2002. Ilmu Mikro Ekonomi. Terjemahan Suhardjono dan Mudrajad. Erlangga. Jakarta.

Soemartini. 2008. Penyelesaian Multikoliniearitas Melalui Metode Ridge Regression. PT Gramdia Pustaka Utama. Jakarta.

Suparmi. 1986. Ekonomi Pertanian. Karunika Jakarta Universitas Terbuka. Jakarta.

Sarifuddin, E. 1992. Efisiensi Penggunaan Faktor-Faktor Produksi Pada Perkebunan Kopi di Kebun Getas/Assinan Banaran, PT. Perkebunan XVII, Tesis, Universitas Gajah Mada.

Tahir, A.G. 2011. Analisis Efisiensi Usahatani dan Resiko Produksi Kedelai Di Sulawesi Selatan. Disertasi. Program Pasca Sarjana Fakultas Pertanian Universitas Gadjah Mada. Yogyakarta. 
